\title{
The Collaborative Training Mechanism of Senior Talent Comprehensive Practice Teaching System of Administration of Innovation and Practice
}

\author{
Liucheng Zhang ${ }^{1, a}$ \\ ${ }^{1}$ The practice teaching management center,Harbin University of Commerce,Harbin,China \\ azhangliucheng@126.com
}

Keywords: Collaborative training . Teaching system. Innovation.

\begin{abstract}
This pape successfully constructed based on the cooperative mechanism of senior talent comprehensive practice teaching system of administration. System design adhere to the education philosophy_ _ "personnel training to meet the need of society, promote the comprehensive development of students". And reflects our characteristic which is "management method fusion, combination of commerce ", implements the implementation, administration and enterprise win-win cooperation for the combination of students' professional ability and cultural quality, achieve the practice teaching, platform construction, the management mechanism, the quality assurance of the elements such as organic unification, blend in our business culture professional practice education, promote the students' ability, development ability and en-trepreneurial innovation progressive type.
\end{abstract}

\section{Introduction}

Of business as the nation's first comprehensive university, in more than half a century of educational practice, the school actively build "to business as the main line, give priority to with management disciplines, outstanding advantage disciplines, strengthening basic disciplines, focusing on application of professional disciplines, multidisciplinary coordinated development of" the structure of the layout. School actively adapt to the development of market economy, in view of the old industrial base of the implementation of a new round of planning adjustment, Heilongjiang and Inner Mongolia northeast border areas development planning and the "two great plains" modern agriculture comprehensive reform's need for senior talents of administration, creatively carried out based on the cooperative mechanism of senior talent comprehensive practice teaching system of administration innovation research and practice.

\section{Comprehensive Practice Teaching System Innovation}

Integrated practice teaching target system.Senior talent comprehensive practice teaching system of administration in cultivating applied, senior specialized talents as the goal, guided by the collaborative innovation teaching idea, outstanding practice teaching link consistency and integrity, perfect the practice teaching content, training students' comprehensive practical ability, promote the students' innovative undertaking ability, meet the needs of economic development for professionals. System of cultivating students of administration not only have the comprehensive quality, and meet the basic quality and a pioneering entrepreneurial personality; Not only has a high level of culture and level and has a strong social adaptation ability and social practice; Not only inherit the "big business, refinement" the precious heritage of traditional culture, but also has the bright time spirit and pioneering consciousness; Not only can well adapt to the society and times, and can in a positive attitude towards life, a high degree of self-awareness and extraordinary creativity to meet the challenge of the new life, create a better future, conform to the requirements of the professional ability of the primary and middle managers, as well as the need to have comprehensive quality. Professional goals of the practice teaching system of three-dimensional of administration, break through the traditional professional practice teaching system of administration research perspective, focusing on solving professional senior talents cultivation of comprehensive ability of administration 
and business culture literacy cultivation problems, for the development of professional education of administration to explore a new talents training mechanism to provide paradigm.

Comprehensive practice teaching content construction.Rely on our advantages characteristic discipline, focus on the construction of national experimental teaching demonstration center of administration, national virtual simulation experiment center, the national college students' practice teaching base of engineering research center, national engineering research center, the ministry of education, business, cultural center, ministry of education, vocational education teacher training base for teaching and scientific research base, such as visual display and problems reveal practice teaching platform, practice content and process training platform, scientific research platform and entrepreneurship, innovation platform four types of national, provincial, and integration of field.

Intuitive display and problems reveal platform. The platform by the national experimental teaching demonstration center of administration management comprehensive practice center, national virtual simulation experiment center - virtual modern enterprise business operation center, the national museum of colleges and universities education alliance - commercial cultural center. Platform laboratory layout is scientific and reasonable, is divided into seven two rooms one hall hall: enterprise resource planning, international business, enterprise manage hall hall hall, hall, shall be of commercial bank, securities and futures, the international logistics hall hall, innovation, entrepreneurship, sand table simulation training rooms and business incubator cultural center. Management comprehensive practice center and virtual simulation experiment through to the modern enterprise the display of process flow and operation link, lets the student emotion understanding of the modern enterprise at the same time, students can also through simulation role, in a real environment comprehensive practical ability and entrepreneurial innovation ability.

Practice content and process training platform .The platform consists of campus practice base and off-campus practice base. Iconic platform are as follows: in the center of the campus construction focus on the national management comprehensive practice and modern enterprise business operating virtual simulation experiment center, off-campus oversize enterprise of China construction bank and financial industry work together for the national college students' practice base. Through the practical teaching method of combining the face-to-face, constantly explore practical training content and process of the construction of many modules platform.

The campus base on to build the professional practice, established and operation simulation practice and virtual modern business environment comprehensive practice of the trinity practical teaching course. Independent development of the modern enterprise business operating virtual simulation large response caused by the innovation course of similar institutions in the country, in professional practice teaching reform of administration in colleges and universities has a leading and demonstration. School combined with industry, professional and enterprise union, in our school there are construction outside the college students' practice teaching base, 236. Through the way of graduation practice, lets the student before entering the station, in a real post exercise comprehensive practice ability, shorten the position to adapt to the time after graduation. Especially in 2013, our school has signed deals with China construction bank, the ministry of education approval, to build national college students' practice teaching base.

Scientific research platform.Platform integrating engineering research center of national engineering research center, the ministry of education and business economic research institute and other scientific research units, giving full play to the advantages of our school discipline resources, combined with industry enterprise, the anti-neoplastic drug re-search, green food industry development, business climate index monitoring in areas such as general major breakthroughs in key technologies and forward-looking technology, building diversified achievements transformation and radiation pattern, promote regional industrial structure adjustment and development of emerging industry. Scientific research achievements into productivity and creative teaching resources effectively, to serve the local economy at the same time, promote the perfection of innovative entrepreneurship education content. By building the government, enterprises, school linkage collaborative innovation education platform, with the government, business enterprise in the docking of innovation education, the teachers and students access to the objective situation and problem 
solving level for learning and practice. And through the enterprise technological innovation design to develop entrepreneurship education training system for innovation, enrich and rich campus innovation entrepreneurship education ways and means of controlling led the students innovative research learning and practice.

Entrepreneurial innovation platform.By multi-platform synergy, integration of inside resources and realize the resources sharing at the same time, the combination of students' professional ability and cultural quality, make the business culture into the practice of innovative entrepreneurship education, make our business characteristic extremely innovative entrepreneurial education platform, to form the "hatch - real entrepreneurial business simulation - campus" of the multi-level teaching mode. Students research, by participating in teachers training college students' innovative undertaking plan practice, college students pioneer park incubation and other activities, master the basic knowledge of innovative undertaking and promote college students' innovative entrepreneurial ability.

Operating mechanism.Senior talent comprehensive practice teaching system of administration in the guiding ideology of the thought of collaborative innovation, in order to enhance students' innovative ability as the breakthrough point, through the system mechanism reform, drive the coordinated development of talent training, scientific research and social service, thus forming the integration of "production" politics of training mode, build "open, integrated and efficient" collaborative training mechanism, emphasize the leading role of school in the practical teaching activities, by implementing the school, enterprises, political parties linkage, collaborative culture, the whole process of dynamic optimization, implementation of cultivating applied of administration, senior specialized talents. Senior talent comprehensive practice teaching of administration coordination management mechanism is mainly embodied in the campus resource integration and synergy between departments, schools and government agencies, industry associations and enterprises of synergy, synergy between domestic universities and communication cooperation with foreign colleges and universities.

The school together. In order to accomplish the coordinated development of integration of Government-Industry-University-Research-Cooperation, at the school level has broken the campus bar type personnel training mode, integration of all the people, money, material resources, to establish "management method fusion, commerce and the combination of" campus multidisciplinary cross training mode, building a diversified practice teaching faculty evaluation system, and attaches great importance to the process set train applied, conformity of practice courses of talent, perfecting examination system and teaching mode. First in a series of school level construction of interdisciplinary teaching and scientific research platform, realize the sharing high quality teaching and research resources, promote the coordinated development of teaching, scientific research, personnel training, build the innovation platform integration, provide the conditions for talent practice innovation of administration in our school, in the service of the, management, engineering, law, literature, science, medicine, art and so on eight 58 undergraduate professional disciplines, and accounting and other professional six national characteristics. Through the campus together, especially in the school of economics, school of accounting, finance and public management institute, school of finance, law and other teaching units achieved between the contribution of resources utilization and cross training cooperation mechanisms.

Outside the school together. School advocates "school combined with industry, professional and enter-prise", depth to carry out the "political implication" cooperative education, for the industry development and local economic construction to cultivate talented person. Stress play a leading role of university, various kinds of our school management actively and scientific research institutes, industries and relevant government functional departments of the cooperation, active communication, actively expand practice teaching related projects, guide the teachers and students to participate in the practice teaching content under the multilateral cooperation. We actively explore the create production practice "double tutors" system, joint development, actively participate in scientific research projects, cooperate to build college practice base and so on. According to different professional, we hire experts and domestic enterprises manager as a school teacher, and colleges and 
universities and government agencies, industry associations and enterprises jointly formulate practical teaching scheme, joint selected faculty, jointly participate in the training process, construction of practice base, combined the research of subject, and jointly promote employment entrepreneurship. Make industry enterprise real subject this professional students' practical ability training. Accounting major and Hal bank selection in the junior students year after year of "clove" class, students after graduation directly to Harbin bank work; Concentrated outside the advantage resources of running a school, to operate professional students built by China construction bank to build national and provincial, field practice teaching base.

"Government-Industry-University-Research-Cooperation", also reflected in the government in the process of transition function, for the enterprise and cooperation of colleges and universities to provide more coordination, financial support and policy guidance. In colleges and universities, government and enterprise, government has to coordinate the authority of colleges and universities, the enterprise interaction. We believe that the third party intervention by the relevant government functional departments, through funding support, policy guide, entrust the measures of the scientific research project, make the government schools, enterprises and form the school enterprise linkage, the collaborative culture of benign interaction.

"Government-Industry-University-Research-Cooperation", the operating mechanism of cooperation to develop is the government, the enterprise needs to closely combined with school education target, through the project of talent fostering and the curriculum system, the social demand to permeate in the course content and practice, the last and the certification exam course contests and synthetically reflected through students graduate employment rate and other indicators, finally realizes the applied, senior specialized talents training target.

International exchange cooperation. Successively with 24 countries and regions of 46 colleges and universities to establish the relationship between the education cooperation and academic exchange. Sign a cooperation agreement in 2012 with the British queen's university Belfast, two school quality management practice teaching resources co-construction and sharing, introducing the original English school of business, economic and other experimental software at the same time, the exchange of communication between teachers and students learn. Service university, South Korea and loosely receive Russia's economy, such as the British queen's university Belfast school students practice more than 100 people, more than 20 schools receive foreign exchange visits. Use practice platform, in the accounting (Canada CGA direction, the chartered accountants, certified public accountants ACCA direction) professional to carry out the practice teaching, greatly improve the students' comprehensive quality and practice ability, high approval and favorable comment by partners. With Britain, Russia, Canada, the United States, Australia, South Korea, Japan and other countries in the practice teaching mode, the information platform construction, design and development of the practice teaching platform, long-term communication and cooperation between teachers and students exchange, etc.

Quality assurance.Teaching quality assurance system including operation system, assessment system, information feedback system, quality assurance system of teaching quality monitoring and security system. Lessons from the practice of open, run, and check all did strict requirements and regulations. Through regular practice teaching evaluation and standardize the three stages (early, mid-term and final) examination, the teaching management process and effect of implement effective monitoring, the "prison" and "control" organic combination, establish a pay attention to the learning process evaluation practice teaching effect evaluation method, forming a closed loop, run effective teaching quality monitoring and security system. Has formulated the practice teaching quality standard ", "practice curriculum management regulation" and other rules and regulations, to ensure the operation of the experimental teaching quality. 
School attaches great importance to the construction of practice teaching, encourage teachers to use to carry out the teaching reform, scientific research and social practice platform application practice, to encourage teachers to study in this paper, the application in practical teaching, enriched the contents of the practice teaching, support and incubate a batch of professional teaching and research achievements, formed the good practice educational atmosphere. The students' practical ability and innovation consciousness is strong, both at home and abroad is obtained in the contest of various fruits, students complete 81 national college students' innovative entrepreneurial training plan projects, being granted more than a variety of extracurricular science and technology innovation and subject contest rewards more than 200, patented 11. Get training students' comprehensive ability, innovation ability get promoted, greatly promoted the application, to achieve the goals of the cultivation of senior specialized talents, schools developing great accountants, actuaries, the cradle of engineers and other senior professional personnel training. Platform has become the government, enterprises, school collaborative innovation of the carrier, in scientific research and innovation, service innovation, talent cultivating innovation has carried on the beneficial exploration. Use platform to actively serve the community, serving local economic development. Through multi-channel cooperation, integration of various resources, make the strategy of green food base, center for economic research, commodity circulation center, service outsourcing research center, and provide intellectual support for regional economic development.

\section{Conclusions}

This paper solves the senior talents of administration discipline intersection and professional knowledge in the practice teaching ability of the integrated application of problems; Solve "political study in the teaching practice of administration" cooperative education mechanism; Solved the comprehensive practice teaching system of administration of incomplete problem; Solve the senior talents of administration business lack literacy problem. Results of a major innovation in practical teaching theory, special major breakthrough in the practice teaching reform practice, to improve the level of professional practice teaching of administration and talent training quality and realizing professional senior talents training goal of administration have made outstanding contributions, in the domestic leading level, in the domestic economy and play a good demonstration role in professional practice teaching, and in Russia, South Korea, Japan, Britain and other parts has produced important influences on international business grow.

\section{Acknowledgements}

This work was financially supported by the Natural Social Science Foundation (15BJY017).

\section{Reference}

[1]Gao Yuan, College students' innovative entrepreneurial training plan of project process management research and exploration [J], Journal of laboratory science, 2013 (6), pp. 71-74.

[2]Yang Weizhi, Using the simulation system to cultivate students ability of enterprise management [J], Journal of laboratory research and exploration, 2013, no. 4, pp. 11-13.

[3]Zhang Li,Applied talents cultivation of innovative thinking mode exploration [J], China's higher education, 2012, (19) , pp.12-13

[4]Chen Yinping, Yin Long, College students' innovative entrepreneurial training plan to carry out the practice and exploration, in Harbin university of commerce, for example [J], Journal of new economy, 2014,(15) , pp. 41-54.

[5]Si Songmen, Zhuang Yale, Thinking about college students' innovative entrepreneurial training program [J], Journal of heilongjiang education (higher education research and evaluation), 2014, (7), pp. 31-33. 